\title{
MORPHOMETRIC STUDY OF PLANTAR ARCH INDEX AND THE PREVALENCE OF FLATFOOT AMONG TRIBES
}

\section{Adjei-Antwi Collins ${ }^{1}$, Chrissie Stansie Abaidoo *2, Nketsiah James ${ }^{3}$, JoshuaTetteh ${ }^{4}$.}

${ }^{1}$ Department of Anatomy, Kwame Nkrumah University of Science and Technology, Kumasi, Ghana.

${ }^{* 2}$ Vice Dean of School of Medicine and Dentistry and Head of Department of Anatomy, Kwame Nkrumah University of Science and Technology, Kumasi, Ghana.

${ }^{3}$ Department of Anatomy, Kwame Nkrumah University of Science and Technology, Kumasi, Ghana.

${ }^{4}$ Department of Anatomy School of Medical Sciences, Kwame Nkrumah University of Science and Technology, Kumasi, Ghana.

\section{ABSTRACT}

Flatfoot (pes planus), commonest foot deformity caused by the absence or collapse of the medial longitudinal arch. Flatfoot results in serious health problems and postural defects. It is highly variable in different populations with many factors associated. This study was conducted to find the plantar arch index and the prevalence of flatfoot and its relationship with tribes in Ghana. A total of 278 participants (172 males and 106 females) with ages ranging from 16 to 34 years were recruited for the study. Ethical approval and participants' informed consent were sought prior to the study. Participants were drawn from the Akan, Ewe, Ga-Dangbe and other tribes (Dagomba, Dagabaa, Frafra, Gonja, Wale Wale etc). Foot imprints were taken from each participant using the ink method. The plantar arch index was calculated using the ratio of the width of the central and the heel region of the footprint. The mean right plantar arch index was higher than the left. The prevalence of flatfoot was $15.1 \%$ (6.1\% unilateral left, $5.8 \%$ unilateral right and $3.2 \%$ bilateral). The prevalence rate was $15.7 \%$ in males and $14.1 \%$ in females. The prevalence rates reported for the Ga-Dangbes and Ewes were $30.8 \%$ and $23.6 \%$ respectively. On the other hand, both Akans and individuals belonging to the other tribes recorded the same prevalence rate of $13.7 \%$. Flatfoot was found to be high among the Ga-Dangbes. Ethnicity as an external factor has a great role in influencing foot arch structure. Also, sex has an influence on the morphology of an individual's foot.

KEY WORDS: Flatfoot, Pes planus, Foot deformity, Medial Longitudinal Arch.

Corresponding Author: Prof. Chrissie Stansie Abaidoo, Vice Dean of School of Medicine and Dentistry and Head of Department of Anatomy, Kwame Nkrumah University of Science and Technology, Kumasi, Ghana. +233208126817 E-Mail: knustsmsanat1@gmail.com

Access this Article online

Quick Response code

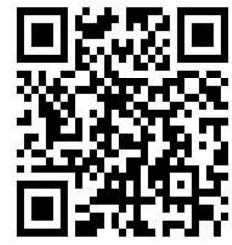

DOI: $10.16965 /$ ijar.2020.221

Journal Information

International Journal of Anatomy and Research

ISSN (E) 2321-4287 | ISSN (P) 2321-8967

https://www.ijmhr.org/ijar.htm

DOI-Prefix: https://dx.doi.org/10.16965/ijar

Article Information

Received: 15 Sep 2020

Peer Review: 16 Sep 2020

Revised: None
Accepted: 09 Oct 2020

Published (O): 10 Nov 2020

Published (P): 10 Nov 2020

\section{INTRODUCTION}

The prevalence of flatfoot reported by different authors varies greatly as a result of the difference in age groups used by these authors [1,2,3].

Geographical location, physical activities and age could be the contributing factors for differences in the prevalence rate of flat foot. Therefore data obtained from one geographical location cannot be applied to a population from a different geographical location. A study conducted by Jaiswal et al. found that, flat foot may affect one of the legs 
or both and flatfoot presents with pain, pressure and instability of the middle structure of the feet [4]. In flatfoot, the total weight of the individual is concentrated in a smaller area on the feet and generates intense pain than normal foot morphology $[5,6]$. Flatfoot is the major reported case at the children's orthopaedic clinic in Europe and America for treatment and management [7]. Affected Ghanaian children are hardly sent to the clinic for proper management and treatment and this can be blamed on the lack of awareness about flatfoot and its attending clinical complication among the Ghanaian populace. Though there have been a lot of studies on the clinical relevance of flatfoot, few studies have been conducted to find the prevalence of flatfoot among the various tribes of the Ghanaian population. Therefore, this study aimed at determining the plantar arch index and the prevalence of flatfoot in selected tribes in Ghana.

\section{MATERIALS AND METHODS}

This study was conducted at the Anatomy Department, School of Medicine and Dentistry, Kwame Nkrumah University of Science and Technology. It spanned the period of September 2018 to June 2019. A total of 278 participants were recruited for the study. 172 were males and 106 were females between the ages of sixteen (16) and thirty-four (34) years. Individuals with no morphological deformities of the feet and willing to participate were included in this study. Individuals having open wounds or injuries on their foot, history of traumatic fracture on the lower limb and orthopaedic surgeries were excluded from the study. The name, gender, age, and ethnicity of the participants were recorded. The ink print method was used to take the footprints of the subjects using the horse black endorsing ink [8]. The plantar arch index was calculated by drawing a tangential line from the medial forefoot edge to the heel region. The central point of this line was then calculated and a perpendicular line was drawn crossing the footprint from the central point. The same method was repeated for the heel tangency point. The value of the Plantar Arch Index is: given as $(\mathrm{PAI})=\frac{A}{B}[9]$. Where, $\mathrm{A}$ is the width of the central region of the footprint (in centimetres) and $B$ is the width of the heel region of the footprint (in centimetres) (Figure 1).

Fig. 1: An image showing the measurement of the width of the central region $(A)$ and heel region $(B)$ of the footprint $(\times 0.2)$.
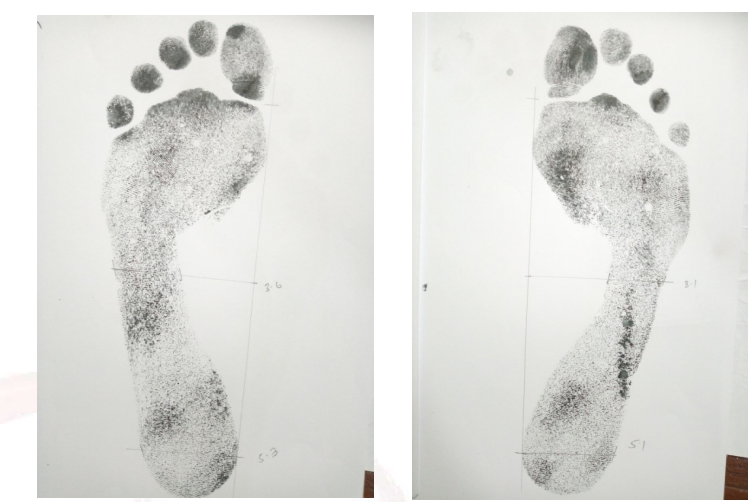

According to the Pediatric Orthopedic Society, a normal plantar arch index is 2 standard deviations (SD) plus the population mean. Thus, plantar arch index values greater than or equal to the sum of 2 standard deviations and the population mean were considered as an indication of flatfoot [7].

Statistical Analysis: The data was then analyzed using IBM Statistical Package for Social Sciences (SPSS) version 20.0. Descriptive statistics (mean, standard deviation and range values) for parameters were represented in the analysis. Normal ranges for both right and left plantar arch indices were also generated in the analysis and tested for significance using the paired T-test. One sample T-test was used to compare the means of other studies. One-way ANOVA was also used in analyzing the parameters stratified by tribes. A probability $(p)$ value of $(0.05)$ was considered statistically significant.

\section{RESULTS}

A total number of 278 participants were recruited for the study. They comprised of 172 (61.9\%) males and 106 (38.1\%) females. The mean age of the participants was $19.73 \pm 2.01$ years (Range: 16 - 34 years). Out of the 278 
participants, 219 (78.8\%) were Akans, 17 (6.1\%) were Ewes, 13 (4.7\%) were Ga-Dangbes and $29(10.4 \%)$ were from other tribes in Ghana. The mean of the right foot central region width was slightly higher than that of the left foot central width. However, the difference between the mean left and right central width of the participants was not statistically significant $(p>0.05)$. The mean left foot heel region width was slightly higher than that of the right foot arch width but the difference between both footprint parameters were not statistically significant $(p>0.05)$.

The mean left central arch width was $3.87 \pm 1.30 \mathrm{~cm}$ for the study population in which the males recorded slightly higher mean left central arch width of $4.10 \pm 1.32 \mathrm{~cm}$ than females who recorded a mean of $3.50 \pm 1.19 \mathrm{~cm}$.
The right foot central region width recorded a mean of $3.96 \pm 1.33 \mathrm{~cm}$ for the study population. Males recorded slightly higher mean right central arch width of $4.21 \pm 1.30 \mathrm{~cm}$ than females who recorded a mean right central arch width of $3.55 \pm 1.28 \mathrm{~cm}$. The right heel region width recorded a mean of $5.16 \pm 0.57 \mathrm{~cm}$ for the study population. Males, however, recorded slightly higher mean right heel width of $5.31 \pm 0.51 \mathrm{~cm}$ than females who had a mean right heel width of $4.93 \pm 0.57 \mathrm{~cm}$. The mean left heel foot region was $5.17 \pm 0.57 \mathrm{~cm}$ for the study population. The difference between all the footprint parameters among males and females were statistically significant $(p<0.05)$ (Table 1).

Table 1: Descriptive statistics and sex differences of the footprint parameters.

\begin{tabular}{ccccccc|}
\hline $\begin{array}{c}\text { Footprint } \\
\text { Parameters }\end{array}$ & Sex & N & Range $(\mathbf{c m})$ & $\begin{array}{c}\text { Mean } \pm \text { SD } \\
(\mathbf{c m})\end{array}$ & T & p-value \\
\hline LA & M & 172 & $1.60-8.40$ & $4.10 \pm 1.32$ & 3.803 & 0.000 \\
\hline & F & 106 & $1.20-7.70$ & $3.50 \pm 1.19$ & & \\
\hline RA & M & 172 & $2.10-8.30$ & $4.21 \pm 1.30$ & 4.113 & 0.000 \\
\hline & F & 106 & $1.40-7.40$ & $3.55 \pm 1.28$ & & \\
\hline & M & 172 & $4.20-7.00$ & $5.31 \pm 0.51$ & 5.741 & 0.000 \\
& F & 106 & $3.70-7.00$ & $4.93 \pm 0.57$ & & \\
\hline & M & 172 & $4.20-7.60$ & $5.34 \pm 0.54$ & 7.052 & 0.000 \\
\hline
\end{tabular}

$\mathbf{L A}=$ Left foot central region; $\mathbf{R A}=$ Right foot central region; $\mathbf{R B}=$ Right foot heel region; $\mathbf{L B}=$ Left foot heel region; $\mathbf{M}=$ Male; $\mathbf{F}=$ Female; $\mathbf{c m}=$ centimetre; $\mathbf{N}=$ sample size; $\mathbf{S D}=$ standard deviation; $\mathbf{T}=\mathrm{t}$-statistic; $\mathbf{p}=$ probability, statistically significant difference $(p<0.05)$

Table 2: descriptive statistics of measured central and heel region widths of the footprint parameters stratified by tribe.

\begin{tabular}{|cccccc}
\hline $\begin{array}{c}\text { Footprint } \\
\text { Parameters }\end{array}$ & Tribe & N & Range (cm) & Mean \pm SD $(\mathbf{c m})$ & p - value \\
\hline LA & Akan & 219 & $1.20-8.40$ & $3.78 \pm 1.23$ & 0.132 \\
& Ewe & 17 & $2.50-8.40$ & $4.33 \pm 1.68$ & \\
& Ga-Dangbe & 13 & $2.40-6.60$ & $4.15 \pm 1.21$ & \\
\hline RA & Other & 29 & $2.30-7.90$ & $4.19 \pm 1.55$ & \\
& Akan & 219 & $1.40-8.30$ & $3.87 \pm 1.26$ & 0.132 \\
\hline \multirow{4}{*}{ LB } & Ewe & 17 & $2.30-8.20$ & $4.56 \pm 1.61$ & \\
& Ga-Dangbe & 13 & $2.50-7.10$ & $4.17 \pm 1.30$ & \\
& Other & 29 & $2.10-8.30$ & $4.19 \pm 1.64$ & \\
& Akan & 219 & $3.90-7.60$ & $5.13 \pm 0.56$ & 0.199 \\
\hline & Ewe & 17 & $4.30-7.40$ & $5.23 \pm 0.76$ & \\
\hline & Ga-Dangbe & 13 & $4.80-6.00$ & $5.41 \pm 0.34$ & \\
\hline & Other & 29 & $4.40-6.50$ & $5.29 \pm 0.62$ & \\
\hline & Akan & 219 & $3.70-7.00$ & $5.13 \pm 0.56$ & 0.187 \\
\hline & Ewe & 17 & $4.50-6.40$ & $5.24 \pm 0.55$ & \\
\hline & Ga-Dangbe & 13 & $4.80-6.40$ & $5.39 \pm 0.48$ & \\
\hline & Other & 29 & $4.30-7.00$ & $5.29 \pm 0.64$ & \\
\hline
\end{tabular}

$\mathbf{L A}=$ Left foot central region; $\mathbf{R A}=$ Right foot central region; $\mathbf{R B}=$ Right foot heel region; $\mathbf{L B}=$ Left foot heel region; $\mathbf{c m}=$ centimetre; $\mathbf{S D}=$ Standard Deviation; $\mathbf{N}=$ Sample size; $\mathbf{p}=$ probability, statistically significant difference $(p<0.05)$ 


\begin{tabular}{|c|c|c|c|c|c|c|c|}
\hline & & & & & & & \\
\hline & Tribe & Parameters & $\mathbf{N}$ & Range & Mean \pm SD & $\mathbf{T}$ & p-value \\
\hline & Akan & LPAI & 219 & $0.22-1.43$ & $0.73 \pm 0.21$ & -1.746 & 0.086 \\
\hline & & RPAI & & $0.30-1.48$ & $0.75 \pm 0.22$ & & \\
\hline plantar arch indices & Ewe & LPAI & 17 & $0.47-1.26$ & $0.81 \pm 0.23$ & -0.281 & 0.037 \\
\hline stratified by tribe. & & RPAI & & $0.49-1.28$ & $0.86 \pm 0.23$ & & \\
\hline & Ga-Dangbe & LPAI & 13 & $0.47-1.27$ & $0.77 \pm 0.23$ & -0.04 & 0.969 \\
\hline & & RPAI & & $0.50-1.25$ & $0.77 \pm 0.22$ & & \\
\hline & Other & LPAI & 29 & $0.49-1.27$ & $0.78 \pm 0.21$ & 0.02 & 0.984 \\
\hline & & RPAl & & $0.43-1.38$ & $0.78 \pm 0.23$ & & \\
\hline
\end{tabular}

$\mathbf{N}=$ sample size; $\mathbf{L P A I}=$ Left plantar arch inde; $\mathbf{R P A I}=$ Right plantar arch index; $\mathbf{S D}=$ standard deviation; $\mathbf{T}=$ t-statistic; $\mathbf{p}=$ probability, statistically significant difference $(p<0.05)$

\begin{tabular}{ccccccc} 
& Tribes & Number & Left foot & Right foot & Bilateral & Total \\
Table 4: Prevalence of & Akan & 219 & $12(5.5 \%)$ & $12(5.5 \%)$ & $6(2.7 \%)$ & $30(13.7 \%)$ \\
flatfoot stratified by tribe. & Ewe & 17 & $1(5.9 \%)$ & $2(11.8 \%)$ & $1(5.9 \%)$ & $4(23.6 \%)$ \\
& Ga-Dangbe & 13 & $2(15.4 \%)$ & $1(7.7 \%)$ & $1(7.7 \%)$ & $4(30.8 \%)$ \\
\multirow{2}{*}{$\%=$ percentage } & Others & 27 & $2(6.9 \%)$ & $1(3.4 \%)$ & $1(3.4 \%)$ & $4(13.7 \%)$ \\
& Total & 278 & $17(6.1 \%)$ & $16(5.8 \%)$ & $9(3.2 \%)$ & $42(15.2 \%)$ \\
\hline
\end{tabular}

The Ewe tribe recorded the highest mean followed by the other tribes. Ga-Dangbe and Akan tribe recorded the lowest mean left foot central region. However, one-way ANOVA showed no statistically significant difference ( $p>0.05$ ) between the observed means of Akans, Ewes, Ga-Dangbes and other tribes. The mean right foot central region width decreased from other tribes through to Ewe, Ga-Dangbe and then to Akans. However, the difference was not statistically significant $(p>0.05)$. The left foot heel region of the Ga-Dangbes, other tribes, Ewes and the Akans recorded a mean of $5.41 \pm 0.34 \mathrm{~cm}$ (range: $4.80-6.00 \mathrm{~cm}$ ), $5.29 \pm 0.62 \mathrm{~cm}$ (range: $4.40-6.50 \mathrm{~cm}$ ), $5.23 \pm 0.76 \mathrm{~cm}$ (range: $4.30-7.40 \mathrm{~cm}$ ) and $5.13 \pm 0.56 \mathrm{~cm}$ (range: $3.90-7.60 \mathrm{~cm}$ ) in a decreasing order respectively (Table 2 ).

The mean left plantar arch index of the Akan tribe was slightly lower $(0.73 \pm 0.21)$ than the mean of the right plantar arch index $(0.75 \pm 0.22)$. There was no difference between the two parameters of the participants of the Akan tribe $(p>0.05)$. The mean left plantar arch index of the Ewes was $0.81 \pm 0.23$ which was slightly lower than the mean of the right plantar arch index $(0.86 \pm 0.23)$. The difference between the left and right plantar arch indices of the participants of the Ewe tribe was statistically significant $(p=0.037)$. The left plantar arch index of the Ga-Dangbes recorded a mean of $0.77 \pm 0.23$ which was the same as the mean of the right plantar arch index of $0.77 \pm 0.22$ of Ga-Dangbe tribe participants. The difference in both left and the right plantar arch index was not statistically significant $(p>0.05)$. Other tribe group recorded a mean of $0.78 \pm 0.21$ and $0.78 \pm 0.23$ for the left and right plantar arch index respectively. The mean of both parameters was the same. The difference in the left and right plantar arch indices was not statistically significant $(p>0.05)$ (Table 3$)$.

Prevalence of flatfoot stratified by tribe: The prevalence of flatfoot in the left and right feet for the study participants was $6.1 \%$ and $5.8 \%$ respectively with a bilateral prevalence of $3.2 \%$. Akan recorded the same prevalence of $5.5 \%$ on each foot. Also, the Akans recorded a $2.7 \%$ prevalence on bilateral feet. A total of $13.7 \%$ prevalence was recorded in the Akan tribe. The Ewes recorded a slightly lower percentage of $5.9 \%$ on the unilateral left than the unilateral right foot prevalence of $11.8 \%$. The Ewe further recorded a $5.9 \%$ prevalence on both feet. The same prevalence of $7.7 \%$ was recorded for Ga-Dangbes for the unilateral right and bilateral foot. The left foot, on the other hand, recorded a prevalence of $15.4 \%$. The other tribes recorded a prevalence of $13.7 \%$. The right foot and bilateral defect recorded the same prevalence of $3.4 \%$. However, the left side recorded a prevalence of $6.9 \%$ (Table 4 ). 


\section{DISCUSSION}

This study recorded a slightly higher mean right plantar arch index of 0.76 than the left plantar arch index of 0.74. Moreover, there was no statistically significant difference between the means for both right and left plantar arch indices $(p=0.057)$. This is consistent with a study by Daniel et al. [10] on Chinese students between the ages of 5 to 9 years, who also observed no statistically significant difference between the left and right plantar arch indices. However, the findings of the present were in contrast with a study by Hernandez et al [9] who observed a significant difference between the mean right plantar arch index and the mean left plantar arch index of the Brazilian population. Geographical location, kind of food, sample size and the types of footwear of the participants could be the probable cause of the difference. Nutrition plays a key role in body growth and development and therefore contributes immensely to inter-population variation; this is because people in different geographical locations consumed different kinds of food with varying nutritional content. Males in the present study recorded slightly higher mean right plantar arch index than the mean right plantar arch index recorded for females. Also, a study in the Brazilian population by Hernandez et al. [9] recorded 0.67 and 0.66 mean right plantar arch index for males and females respectively. A study in a Southeast Nigerian primary school, pupils also recorded a mean right plantar arch index of 0.84 and 0.82 for males and females respectively though the difference between the plantar arch indexes was not statistically significant [11]. The higher mean right plantar arch index in males could be due to activities, exercises and types of footwear worn by the males $[6,12,13]$.

Based on the criterion recommended by the Pediatric Orthopedic Society, the set limits for flatfoot was given as, 1.16 for the left foot and 1.20 for the right foot irrespective of the sex and tribe of the participant. In this study, the prevalence of flatfoot was $15.1 \%$. This was consistent with a study by Senadheera et al. [14], in which the prevalence of flatfoot was $16.1 \%$. Also, in a comparative Ezeukwu et al.
[15] recorded a $14.8 \%$ prevalence of flatfoot. Conversely, the prevalence of flatfoot recorded by Ezemagu et al. [16] among Nigerians and Indian populations by Rithanya et al. [17] were $6.2 \%$ and $10.0 \%$ respectively which were lower values. Also, a higher prevalence of $25.0 \%$ was reported by Umar and Adeyemi, [18] among the Yoruba Ethnic group of Nigeria. The differences in the prevalence could be due to the differences in age geographic location, activities of the participants, sample size and genetic make-up. The prevalence of unilateral flatfoot of the left and right feet of the present study was $6.1 \%$ and $5.8 \%$ respectively. This was consistent with a study conducted by Pranati et al. [7] among adolescents aged between $14-20$ years in a South Indian population. They recorded left and right unilateral flatfoot prevalence respectively as $6.0 \%$ and $2.0 \%$.

\section{CONCLUSION}

In the present study, the prevalence of flatfoot in the study population was $15.1 \%$. Also, unilateral flatfoot prevalence of the left foot was $6.1 \%$ and the right foot was $5.8 \%$. A bilateral prevalence of $3.2 \%$ was recorded. Males recorded flatfoot prevalence of $15.7 \%$ whilst females recorded $14.1 \%$. The Akan tribe recorded the same prevalence of $13.7 \%$ with the other tribes. Also, the Ga-Dangbes recorded the highest prevalence of flatfoot of $30.8 \%$. The Ewes recorded a prevalence of 23.6\%. The Akans, the Ewes, the Ga-Dangbes and other tribes recorded the prevalence of unilateral left flat feet of 5.5\%, 5.9\%, 15.4\% and $6.9 \%$ respectively. The unilateral right flatfoot prevalence recorded among the Akans, Ewes, Ga-Dangbes and other tribes was 5.5\%, $11.8 \%, 7.7 \%$, and $3.4 \%$ respectively. However, the bilateral prevalence recorded among the Ga-Dangbes, Ewes, other tribes and the Akans were $7.7 \%, 5.9 \%, 3.4 \%$ and $2.7 \%$. The present study has therefore provided knowledge on the prevalence of pes planus in Ghana.

\section{Conflicts of Interests: None}

\section{REFERENCES}

[1]. Daneshmandi, H., Rahnema, N. and Mehdizadeh, R. Relationship between Obesity and Flatfoot in High-school Boys and Girls. International Journal of Sports Science and Engineering 2009;3(1):043-049. 
[2]. Bhoir, T., Anap, D. B. and Diwate, A. Prevalence of Flat Foot among 18 -25 Years Old Physiotherapy Students: Cross Sectional Study. Indian Journal of Basic and Applied Medical Research 2014;3(4):272278.

[3]. Periya, S. N. and Alagesan, J. Prevelence and incidence of flat foot among Middle East and Asian Population:An Overview. International Journal of Pharmaceutical Science and Health, 2017;4(7): 8-9.

[4]. Jaiswal, K. K., Patel, V. and Nagekar, K. Study of correlation between planter arch index and BMI in young adults. International Journal of Current Research 2018;10(08): 72948-72953.

[5]. Singrolay, R. and Singh, R. K. Staheli's plantar arch index measured by simple footprint method is an effective diagnostic tool for flat foot as other radiological methods- A comparative study. International Journal of Science and Research, 2015;4(2277): 81-83.

[6]. Vangara, S. V., Gopichand, P. V., Bedi, M. and Puri, N. Effect of barefoot walking on foot arch structure in Tribal children. Asian Journal of Medical Sciences, 2016;7(5): 108. https://doi.org/10.3126/ajms.v7i5.15241

[7]. Pranati, T., Yuvraj Babu, K. and Ganesh, K. Assessment of plantar arch index and prevalence of flat feet among south indian adolescent population. Journal of Pharmaceutical Sciences and Research, 2017;9(4):490-492.

[8]. Ampong K. An anthropometric study of footprint dimensions as a model for height and sex determination in Ghana. Unpublished Mphil thesis, KNUST; 2017;1-115.

[9]. Hernandez, A., Kimura, L. and Laraya, M. Calculation of Staheli's Plantar Arch Index and Prevalence of Flat Feet/ : a Study With 100 Children Aged 5-9 Years. Acta Ortopédica Brasileira 2007;15:68-71.

https://doi.org/10.1590/S1413-78522007000200001

[10]. Daniel, D. K., Chandrasekaran, C. and Mano, A. A Study on Prevalence of Flat Feet Among School Children in Kanchipuram Population. International Journal of Anatomy Research, 2015;3(3):12401244. https://doi.org/10.16965/ijar.2015.201

[11]. Ibikunle, P. and Ikekwem, E. C. Prevalence of pes planus and its associated factors among primary school pupils aged 8- 12 years in southeast Nigeria. Nigerian Journal of Medical Rehabilitation, 2017;19(1):1-19. https://doi.org/10.34058/ njmr.v19i1.164
[12]. Chang, J.-H., Wang, S.-H., Kuo, C.-L., Shen, H. C., Hong, Y.-W. and Lin, L.-C. Prevalence of flexible flatfoot in Taiwanese school-aged children in relation to obesity, gender, and age. European Journal of Pediatrics, 2010;169(4): 447-452. https://doi.org/10.1007/s00431-009-1050-9 PMid:19756732

[13]. Bhattacharjee, N. and Goswami, M. Footprint analysis and prevalence of flatfoot: A study among the children of South 24 Parganas, West Bengal, India. Anthropological Review, 2017;80(4):369380. https://doi.org/10.1515/anre-2017-0026

[14]. Senadheera, V. V, Nawagamuwa, B. M., Nidhya, K., Sivappriyan, S., Warnasooriya, W. M. S. M., Madhuranga, P. M. and Peiris, H. R. D. Prevalence and associated factors of flatfoot among 6 to 10 aged children in central province of Sri Lanka. International Journal of Physiotherapy 2016;3(3):310-315.

https://doi.org/10.15621/ijphy/2016/v3i3/100834

[15]. Ezeukwu, A. O., Orji, E. A., Okezue, O. C. and Ezugwu, $U$. A. Foot anthropometric measurement of primary school Children with and without flatfoot: $A$ comparative study. Online Journal of Health and Allied Sciences, 2018;17(2): 1-5.

[16]. Ezemagu, U. K, Nwokporo, A. Uchenna, Egwu A. J. and Uzomba, G. C. An Assessment of Plantar Arch Indexes and Prevalence of Flat Foot (Pesplanus), in Relation to Occupations in Ikwo L.G.A of Ebonyi State, Nigeria. International Journal of Medicine and Pharmaceutical Science, 2018;8(6): 9-18. https://doi.org/10.24247/ijmpsdec20182

[17]. Rithanya, P., Babu, K. Y. and Mohanraj, K. G. Assessment of flat foot by plantar arch index using footprint in aged population. Drug Inventor Today, 2018;10(11): 2142-2145.

[18]. Umar, M.B. T. and Adeyemi, P. Incidence of Pes planus and Anthropometric Comparison between Flat and Normal Foot of the Yoruba Ethnic Group of Nigeria. Research Journal of Applied Sciences, 2010;5(6):412-416. https://doi.org/10.3923/ rjasci.2010.412.416

How to cite this article:

Adjei-Antwi Collins, Chrissie Stansie Abaidoo, Nketsiah James, JoshuaTetteh. MORPHOMETRIC STUDY OF PLANTAR ARCH INDEX AND THE PREVALENCE OF FLATFOOT AMONG TRIBES. Int J Anat Res 2020;8(4.1):7782-7787. DOI: 10.16965/ijar.2020.221 